\title{
Development of Commuter Booking Software for Road Transport Company
}

\author{
Esiefarienrhe Bukohwo M. \\ University of Agriculture, Makurdi \\ Benue State \\ Dept. of Maths/Stat/Computer \\ Science
}

\author{
Malik Rufai Adeiza \\ Federal University Lokoja \\ Kogi State \\ Dept. of Computer Science
}

\author{
Ataguba Grace Ejura \\ Kogi State College of Education \\ Ankpa, Kogi State \\ Dept. of Computer Science
}

\begin{abstract}
Transportation Industry is an organization that had been in existence and Businesses within this industry have a much greater amount of exposure to the public than many other industries. About $80 \%$ of the nation people use this medium as a means of their transit, either goods from one place to the other. Besides it's widely used, it faces a lot of challenges, because most organizations in the business use manual approach of handling their Customers information.

The research paper addresses this approach and it is achieved by providing an automated system for processing customer's information. Programming is performed using PHP Platform, and MySQL 4.1. Online Customer Care Service is created using wired and wireless LAN networks
\end{abstract}

Keywords: Customer Care Service, LAN and Internet.

\section{INTRODUCTION}

Businesses within the transportation industry have a much greater amount of exposure to the public than many industries [5]. Consider that many transportation companies not only maintain a customer service department, but have ongoing contact with customers through their drivers, agents, sales representatives and logistics coordinators. Thus, improving customer service in a transportation firm extends far beyond merely improving the customer service department [1].

Customer Care is a fundamental building block of business success. Each time you have contact with your customers, you have an opportunity to improve your standing with them and augment the prospect of further businesses. Customer care service is a series of activities designed to enhance the level of customer satisfaction i.e. the feeling that a product or service has met the customer expectation $[4,10]$. Almost every aspect of your business affects the way your customers view your business. There are also specific programs you can put in place to increase your level of Customer Care. This guide outlines what customer care involves. It explains how you can use customer contact, feedback and loyalty schemes to retain existing customers, increase your relations to them and even win new customers

\subsection{Statement of Problem}

Owing to;

i. Difficulties faced in terms of tracking customers' data when need arise.

ii. Time wasted in manual processing of customers' information

iii. The difficulties customers' faced when needs to lodge complains.
The purpose of this study is to put to an end to the difficulties both the organization and customers' encountered during accessing/checking of information and making easy access relations between customers and the organization. This is achieved by developing a computerized Customer Care System which is user friendly and interactive.

With the growth in information technology, the study offers numerous benefits to the New Nyanya Motor Park and to any organization that deals on customers' information.

\subsection{Scope of Study}

This work is centered to New Nyanya Motor Park. It deals with the development of online customer care system for the organization to enhance the growth of the company.

\subsection{LITERATURE REVIEW 2.1 Customer Service}

Customer service is a series of activities designed to enhance the level of customer satisfaction [4]. It is the provision of service to customers before, during and after the services [8]. Its importance varies by industry and customer. Customer service may be provided by a person (e.g. sales and service representatives), or by automated means.

Customer trust can be destroyed at once by a major service problem, or it can be undermined one day at a time, with a thousand small demonstrations of incompetence. Customer service plays an important role in an organization's ability to generate income and revenue. From that perspective, customer service should be included as part of an overall approach to systematic improvement [6].

Some have argued that the quality and level of customer service has decreased in recent years, and that this can be attributed to a lack of support or understanding at the executive and middle management level of corporation and/or a customer service policy.

To address this argument, many organizations have employed a variety of methods to improve their customer satisfaction levels [9].

\subsection{Instant Feedback}

Recently, many organizations have implemented feedback unit that allows them to capture feedback at the point of experience. For example, National Express, one of the UK's leading travel companies encourages passengers to send text messages whilst on transit. This has been shown to be useful as it allows companies to improve their customer service before the customer faults, thus making it far more likely that the customer will return next time. A challenge working with customer service is to ensure that you have focused your 
attention on the right key areas but the challenge is to select a few which reflects your overall strategy. In addition to reflecting your strategy it should also enable staff to limit their focus to the areas that really matter. The focus must be of those which will deliver the most value to the overall objective, e.g. cost saving, service improving etc. It must be done in such a way that staff sincerely believes that they can make a difference with the effort [2].

\subsection{Understand Your Customer}

Govond, S. [4] states that, in business-to-business trading, e.g. transporters" company providing a high level of customer care often requires you to find out what your customers want. Once you have identified your most valued customers or best potential customers, you can target your highest levels of customer care towards them. Another approach, particularly in the customer care unit of the organization, is the obligation to treat all customers to the highest standard [9].

\subsection{Manage Your Customer Information}

It is important that you draw up a plan about how customer information is to be gathered and used. Establish a customer care policy. Assign a senior manager as the policy's champion but make sure that all your staff is involved - often less senior staff has more direct contact with customers. You can manage your customer records using a database or customer relationship management software [8]. Information about your customers and what they want is available from many sources, including;

a. Records of their contacts with your organization phone number, names, etc.

b. Changes in the overall success of specific services

Where possible, also measure your customer service levels by putting systems in place to assess your performance in business areas which significantly affect your customers' satisfaction level. Identify key performance indicators (KPIs) which reflect how well you are responding to your customers' expectations.

For instance, you might track;

- The number of queries or complaints about your products or services

- The number of complaints about your employees

- The number of contacts with a customer each month

There are important areas of customer service which are more difficult to measure. Many of these are human factors such as a receptionist's telephone manner or a desk's conduct while visiting clients (customers). In these areas, it is crucial that you get feedback from your customers about their perceptions of your customer service [7].

\subsection{Enhancing Organizational Plan by using Customer Care}

There are a number of techniques you can employ, including;

a. Providing a free customer helpline b. Answering frequently asked questions on your website

c. Offering preferential discounts to existing customers on any special deals

\section{RESEARCH METHODOLOGY}

Methodology is the study of how to perform scientific research. It essentially contains specifications for the design and coding of the applications. Many methodologies include a diagramming notation for documenting the results of the procedure; approach for carrying out the procedure.

There are different types of research methodologies which include;

i. Object-Oriented Analysis and Designed Methodology (OOADM)

ii. Structured System Analysis and Design Methodology (SSADM)

iii. Extreme Programming Methodology

iv. Prototyping Methodology

\subsection{Methodology Adopted in the Research}

In this project analysis, SSADM was adopted because of its simplicity. SSADM does not require special skills and can easily be taught to the staff. Normally, common modeling and diagramming tools are used. 3.2 Analysis of the Existing System

The existing system is a system that is been carried out in terms of manual operation.

Critical analysis of this system reveals that it is a system prone to a lot of errors and it is not effective and searching for somebody's information is time consuming and boring. Careful analysis also shows that because of the complexities of the manual system, information stored is difficult to retrieve.

Also because of the inconsistency of the manual system, at times files and items are lost because of mismanagement.

Another problem of this manual method is that customers (passengers) do not have easy access to lay their complaint.

\subsection{Objectives of study}

The objectives of the proposed study are listed below;

To develop software called online Customer care system that will replace the manual method.

- To develop, promote, and provide adequate and efficiently online Help Desk/Customer Care System.

- To eliminate the error involved with the manual method of checking customers' information and also to save time wasted with manual method.

To maintain an efficient system of collection, sorting and delivery of customers information. 


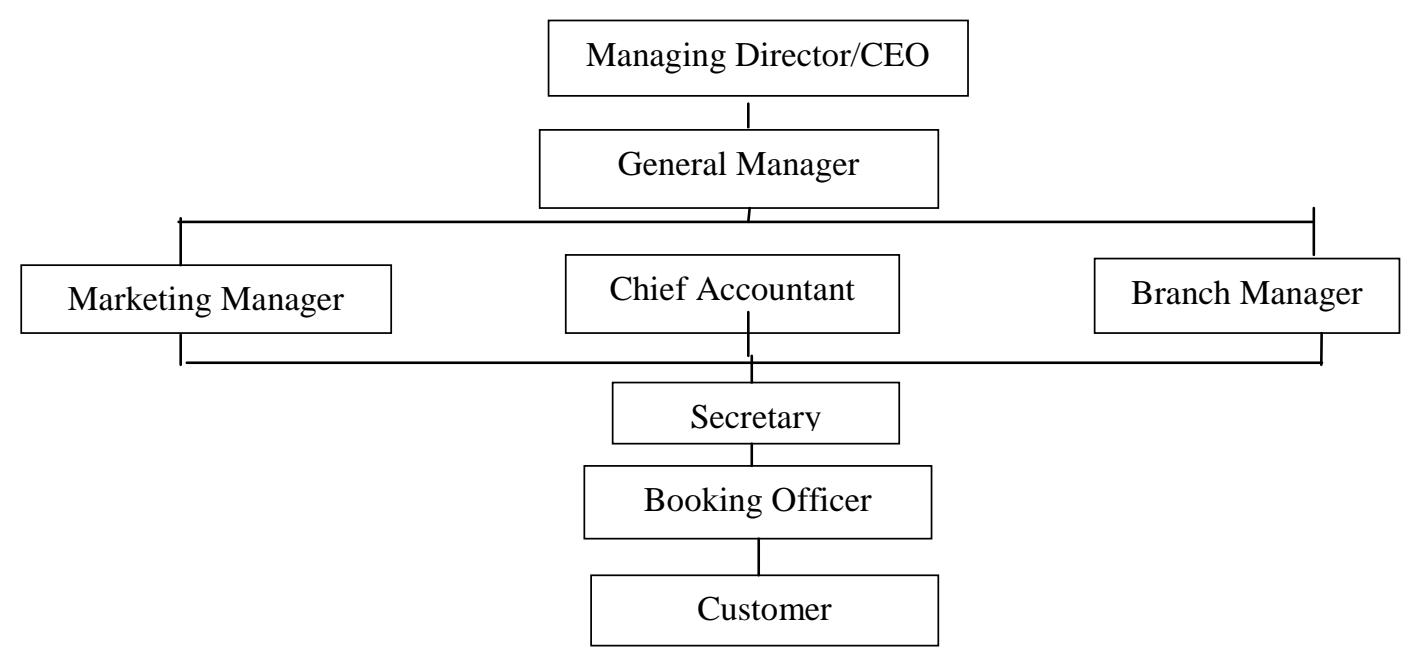

Figure 1: Organizational Structure

\subsection{Problems of the Existing System}

A lot of problems are associated with the existing systems. The existing system involves the use of manual way to check customers' information, also to give customers' access other organization and store data/information.

The system has proved detective as the objective of the system has also failed. Among the problems associated with the existing system include the following;
i. Data redundancy
ii. Difficult to access the company
iii. Time wasting in searching/sorting for information
iv. Data/information loss or misappropriate of customers' information
v. Poor security and protection
vi. Poor platform for suggestions and complains.

Reminders if deadlines are passed without action. The entire system is more efficient since submissions can be both accessed and transmitted far more quickly than would be the case for a paper based system

\section{RESULTS AND DISCUSSION}

\subsection{Design of the New System}

The major factor taken into consideration in the design of the new system is the issue of having easy access to the company either for booking ticket or for complain in an electronically format. The new system is made into modules that can be used to book ticket or mailed for suggestions/complain.

\subsection{Software Requirement}

The following software is needed for adequate implementation of the design

$$
\begin{array}{ll}
\text { i. } & \text { Window + starter/window XP } \\
\text { ii. } & \text { PHP } \\
\text { iii. } & \text { MySQL } 4.1 \\
\text { iv. } & \text { Internet explorer/Mozilla Firefox }
\end{array}
$$

\subsection{Hardware Requirement}

The following hardware is required for the efficient work of the system;
i. At least 500 gigabyte of hard disk
ii. At least $2 \mathrm{GBB}$ of RAM
iii. At least $2.0 \mathrm{MHz}$ of speed processor etc.



Figure 2: Procedure Chart 


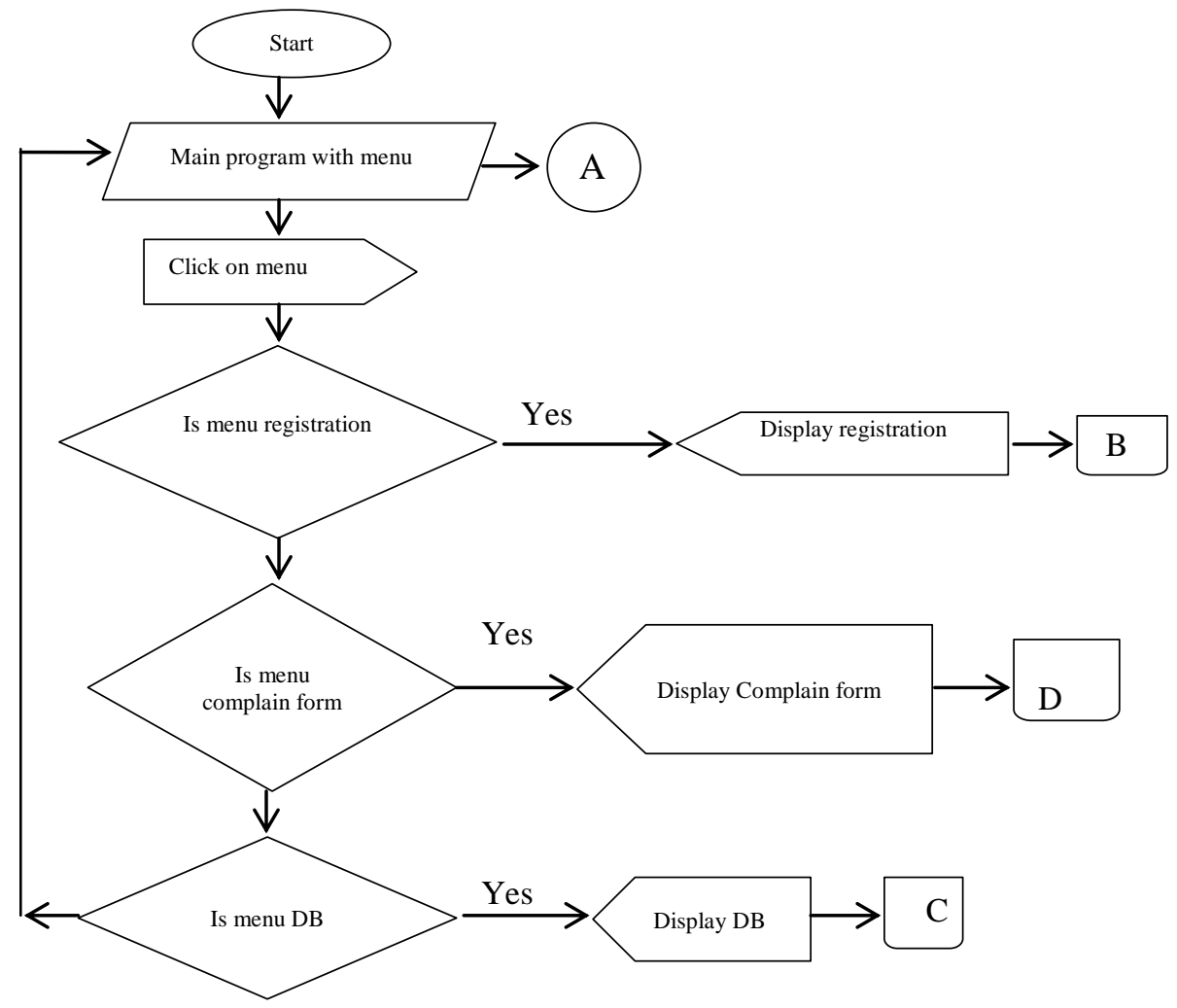

Figure 3: Main Flowchart

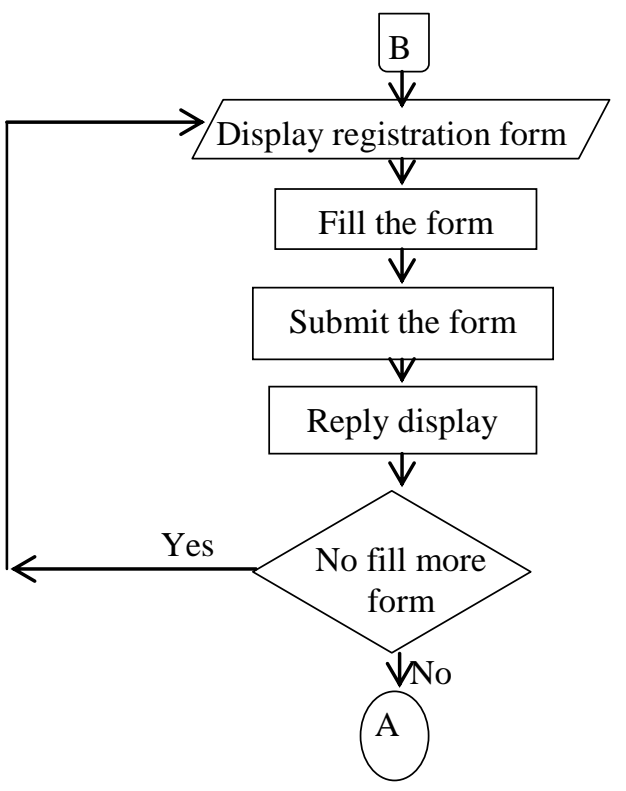

Figure 4: Registration Flowchart

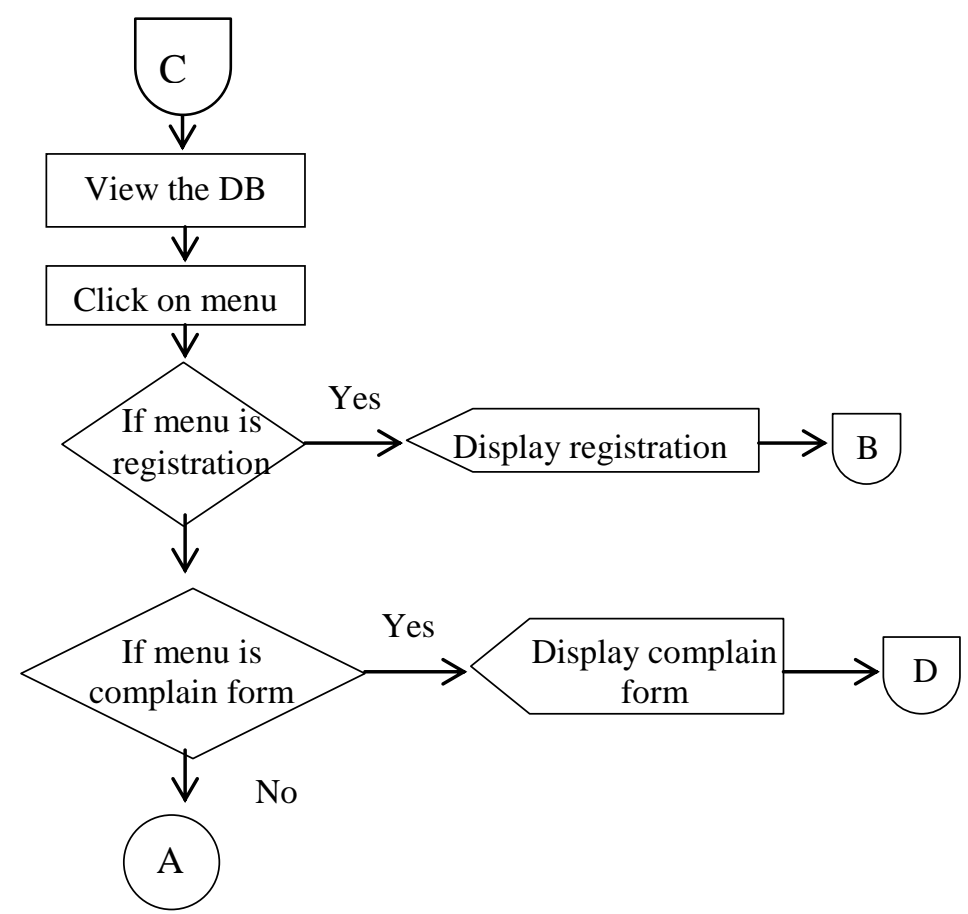

Figure 5: Database View 


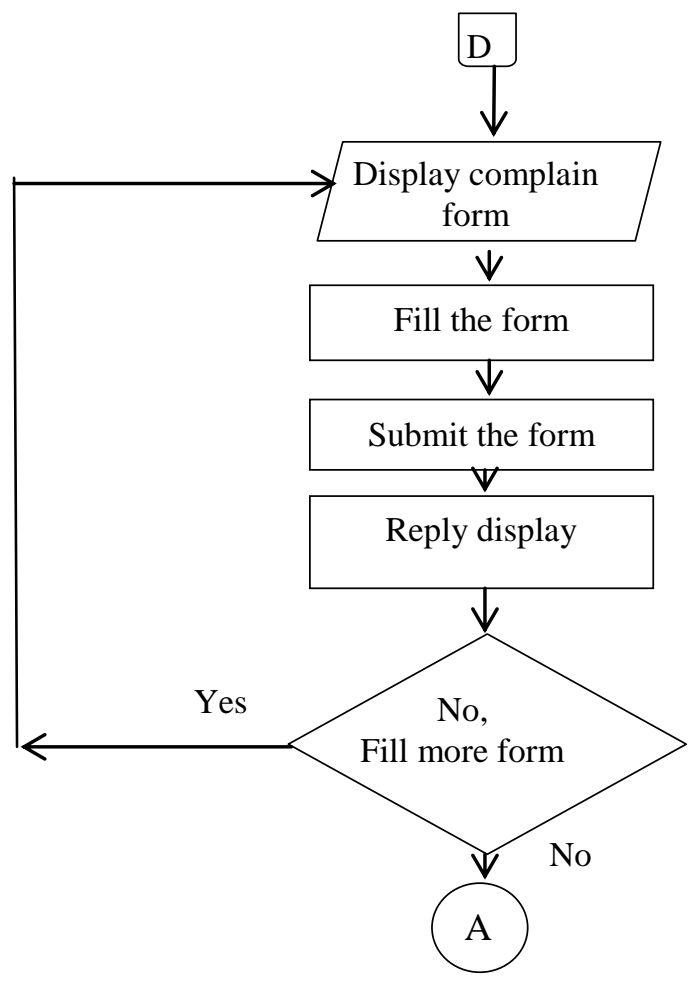

Figure 6: Complain Flowchart

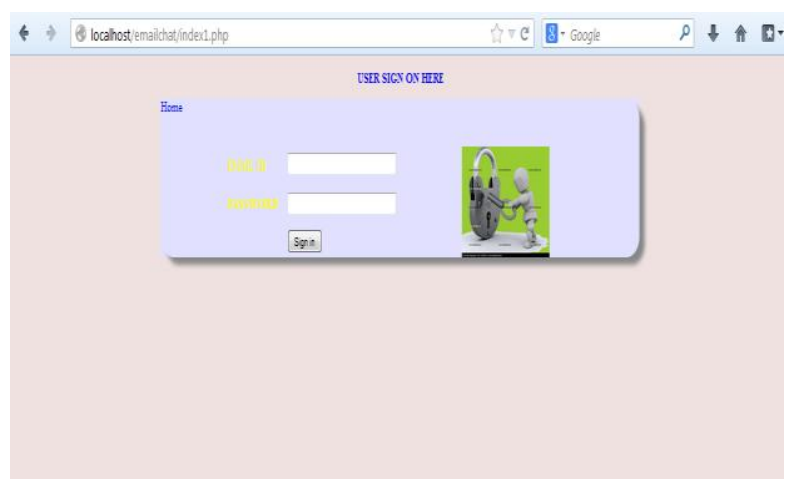

Figure 7: Login Page

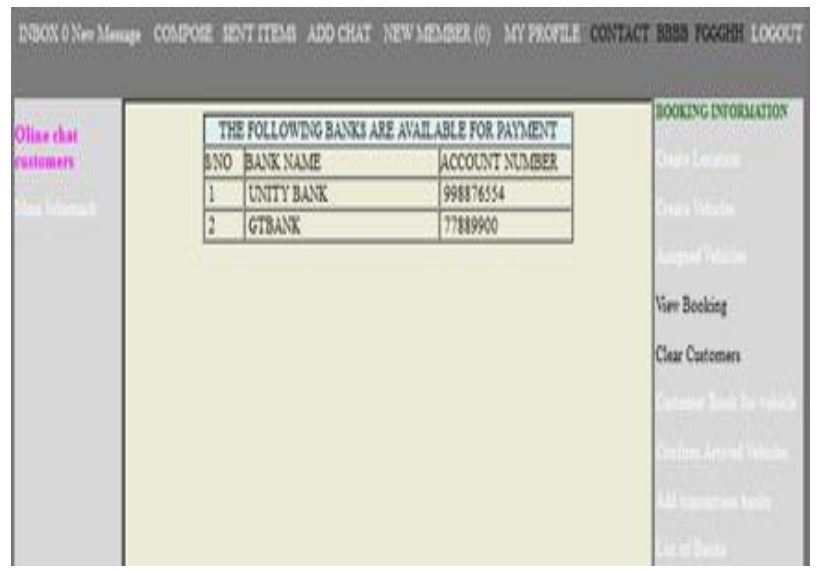

Figure 8: Available banks

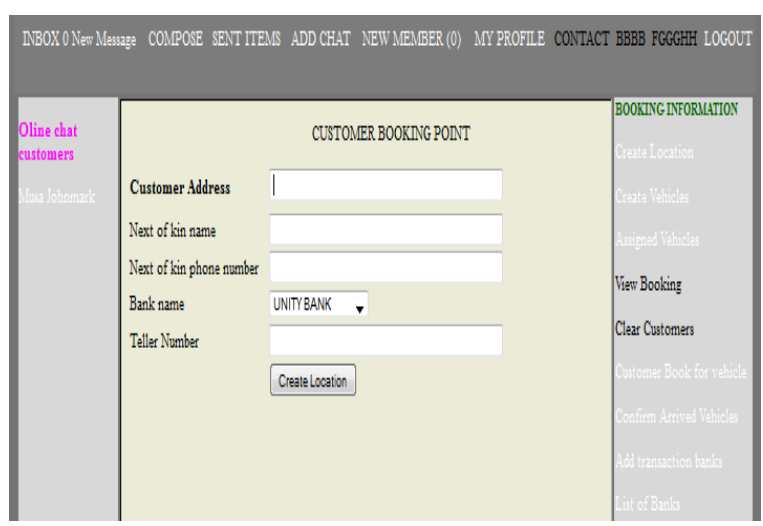

Figure 9: Customer Information page

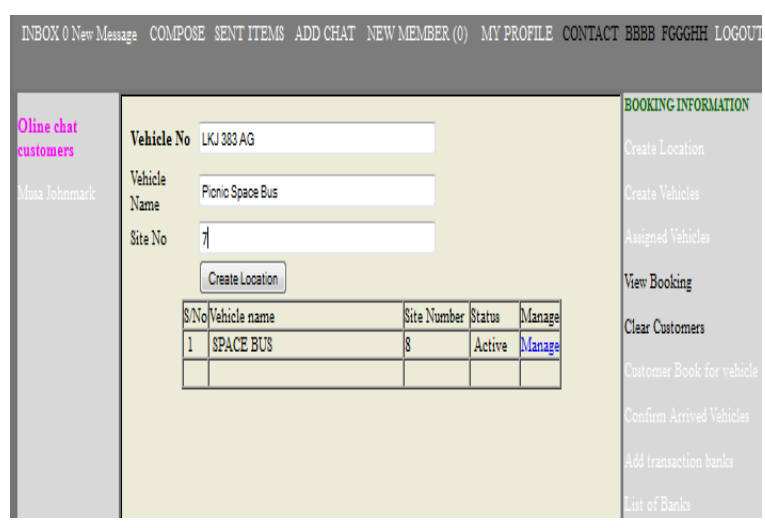

Figure 10: Booking page 


\subsection{System Documentation}

The software was designed to be user friendly. It can be operated by anyone irrespective of their education level provided that the instruction is followed. The software runs on window operating system platform. The program also requires internet like explorer, Mozilla Firefox e.t.c.

\section{SUMMARY}

The manual ways of checking customers' information for customers to have access to the company are being replaced by the online Customers' Care System. Most organization now employs it because of exceptional profit derived from online customers' care system.

The instant message is made available. The customers love to see that you are not mainly after their money. And really you are not. Or at least you should not be. You are after a successful business that will supply your wealth over a period of time when you have worked at it, not beforehand.

Surveys suggest that service driven companies are able to charge up to $9 \%$ more for the goods and services they offer and grow twice as fast as the average. These are powerful in any industry. Equally, poor service has a cost penalty. It costs up to five times as much to go out and get a new customer as to retain those we have [4].

\subsection{Conclusion}

The importance of good customer care matters because keeping existing customers is easier than finding new ones and satisfied customers will do a lot of our advertising for us. Most people consider doing business with a certain company because of recommendation by a friends or acquaintance (associate). Dissatisfied customers spread the bad news and undermine your business.

Therefore, your objective must be to provide the highest standard of customer care possible and to always aim for excellence. A customer who feels good doing business with you and through you, the company is more than likely to stay with you and recommend you to others. Giving first is essential to your growth so put the client first every time, even if it costs you more now.

The software developed in this paper is for Commuters using Road as a means of transportation. The work does not stop here; much work can be done in future. However, there are still many gaps to be filled by making this system more effective. This needs more modifications to build an integrated system for Commuters of all kinds of transportation systems. Therefore this research serves as the basis for the deeper research on transportation modeling for the researchers in the field of software development.

\subsection{Recommendations}

For the online Help Desk Care System to be effective, I recommend the following;

i. For New Nyanya Customers' Care System

- Having access to internet

- Having a well-designed website

- $\quad$ Strong and reliable database

- $\quad$ IT inclined staff

ii. For the government to provide the following too;

- Government should ensure necessary infrastructure

- Masses should be educated on the use of information technology

\section{REFERENCES}

[1] Buchanan, Leigh "A Customer Service Makeover". Inc. magazine. Accessed 29 Oct 2012.

[2] Dall, M. (2004).Winning the war against customer disservice. London: MacMillan Publisher.

[3] Solomon, Micah. "Seven Keys to Building Customer Loyalty-and Company Profits". Fast Company. Accessed 29 Oct 2012.

[4] Govonds, S. (2005). Customer Information System. London; Anshan Publishers.

[5] What Is Customer Service? - Definition, Types \& Role in Marketing. http://study.com/academy/lesson/what-iscustomer-service-definition-types-role-in-marketing.html 19: 34pm, 18th May, 2015

[6] Peter, S. (1999). Credit Management System. Texas: Mark Publishers.

[7] Phil, S. (2002). Customers' Relationship Management. New York. HBR Publication.

[8] Schmitz, B. H. (2009). Customer Experience Management: A Revolutionary Approach to Connecting with your Customers. England: Willey Standard Press.

[9] Turban, E. (2002).A Managerial Perspective. New York: Prentice Hall Publisher.

[10] White, I. (2004). Customers Information. Texas: Mark Publisher. 